\title{
OS ESTUDOS DO TEMPO NA GEOGRAFIA HUMANA BRASILEIRA
}

\author{
ROSANA FIGUEIREDO SALVI ${ }^{1}$
}

SALVI, R. Os Estudos do Tempo na Geografia Humana Brasileira. Semina: Ci. Soc./Hum., Londrina, v. 15, n. 3, p. $250-259$, set. 1994.

RESUMO: O trabalho objetiva compreender as concepções de Tempo na Geografia Humana Brasileira desde a escola clássica atê os dias atuais, com especial ênfase nas proposições de Milton Santos entre outros geógrafos contemporâneos.

PALAVRAS-CHAVE: Geografia, Tempo, Temporalidade, Espaço, História, Historicidade, Evolução do conhecimento geográfico, Epistemologia da Geografia.

\section{1 - INTRODUÇĀO}

Segundo ANDRADE (1989), estudioso da evolução do pensamento geográfico brasileiro, a formação de uma geografia brasileira com caráter eminentemente científi$\mathrm{co}$, deu-se a partir da década de $30 \mathrm{com}$ a criação do IBGE e das Faculdades de Filosofia, Ciências e Letras, onde funcionavam os cursos de Geografia e História.

Três tendências originais teriam contribuído na formação dos geógrafos brasileiros.

A tendência dos estudos geográficos ligada ao IB. GE exprimiu-se na geopolitica com base ratzeliana até os anos 40 e 50 , estando sua preocupaçäo voltada para uma nova divisão territorial que projetasse o Brasil no continente sul-americano. São representantes desse periodo Teixeira de Freitas, Everardo Backheuser e militares como Mario Travassos e Osório da Rocha Diniz.

A tendência verificada nas Faculdades de Filosofia, Ciências e Letras, foi voltada para a formação de professores de ensino médio, tendo-se originado a partir de Delgado de Carvalho - geógrafo formado na França - e em 40 e 50 passaram seus estudantes a integrar o quadro de pesquisadores do IBGE.

Assim, o estudo do espaço brasileiro nas escolas de Filosofia iniciou-se dentro dos modelos da escola geográfica francesa, vindo muitos professores franceses trabalhar no Brasil como Pierre Deffontaines, Pierre Mombeig e Francis Ruellan. Essa influência passaria a ser característica também no IBGE a partir de 1940, perlodo explosivo para os Boletins Geográficos e para a Revista Brasileira de Geografia.

Uma outra tendência inicial do pensamento geo- gráfico estaria expressa nos "ensalstas" como Gilberto Freire, Josué de Castro e Caio Prado Júnior.

Essas três vertentes consolidaram a geografia brasileira e nos preocuparemos aqui com a evolução da Geografia nas escolas de Filosofia, onde as mudanças no pensamento geográfico deram-se por etapas, em fases que vão de 1930 a 1960 ; de 1960 ao final de 1970 e de 1980 em diante. Essas subdivisões são marcadas por polêmicas que se verificam nas discussões geográficas. Nos prenderemos àquelas cuja preocupação com a análise temporal foram e são expressas.

Iniciaremos o trabalho considerando a natureza das formulações teóricas sobre o tempo. Após tais consideraçöes, faremos uma rápida exposição dos procedimentos analíticos da Geografia Clássica segundo seu teor temporal e, finalmente ${ }_{s}$ nos preocuparemos mais detalhada mente com a concepção atual dessa temática através dos seus mais significativos propositores.

\section{2 - A NATUREzA dAs formulacōes TEÓRICAS SOBRE O ESPAÇO E O TEMPO}

Algumas das polêmicas conceituais sobre o espaço e o tempo, dizem respeito à determinação dos elementos espaço-temporais, à qualidade de se reduzirem uns aos outros ou de se reduzirem a coisas e eventos e à consequência das diferenças ontológicas dessas conceituaçōes.

As teorias que propõem que o espaço e o tempo são redutiveis a coisas e eventos são chamadas "teorias relacionais", enquanto as que defendem a sua irredutibilidade, são denominadas "teorias absolutas".

Com relação ao tempo, as teorias podem caracteri-

1 - Departamento de Geociências/CCE - Universidade Estadual de Londrina, Fone: (043) 321-2000 - Ramal 4246, Caixa Postal 6001, Londrina, Paraná, Brasil, CEP 86051-970. 
zar tanto eventos físicos, quanto mentais. As que sustentam a primeira definição recebem o nome de "teorias objetivas", enquanto as que sustentam a segunda definição recebem o nome de "teorias subjetivas".

Com respeito a forma das estruturas temporais, existem elaborações mentais e também sistêmicas que se dão a partir de noções como a de tempo cíclico, a de tempo cronológico, a de tempo contínuo, a de tempo retilineo, a de tempo rítmico, a de tempo métrico, etc.

Houve ainda várias concepçóes analíticas do tempo, sendo suas diferenciações estipuladas pelas diferentes åreas interessadas.

O problema do tempo pode ser estudado sob o aspecto psicológico, ou seja, como é que nós o apreendemos. É a impressão do "antes" $e$ "depois" que as coisas gravam na mente; o sentimento de presença das imagens que se sucedem, sucederam ou hão de suceder, referidas a uma anterioridade. O tempo psicológico não é mais do que a percepção dessa sucessão contínua no campo da consciência com aspecto de localização e de anteriorida. de: o tempo pertence à consciência.

O tempo pode ainda ser analisado sob o aspecto ontológico, ou seja, como ele é em si mesmo. Para ser estudado na sua metafisica, não se pode dividi-lo no "antes" e no "depois", mas considerá-lo na sua sintese de continuidade. Assim, o tempo é tido como indivisivel $l_{g}$ pois ele não e̊ apenas uma sucessão de instantes separa dos, mas sim, um contînuo e, como tal, indivisivel.

Existe o conceito de tempo vital ou biológico, que se revela nos sinais do envelhecimento, por exemplo.

Hả, ainda, a concepçäo de tempo astronômico, que pode ser exemplificado nas medições efetuadas para calcular -se a duraçâo do dia e da noite.

Existem também a concepçăo do tempo social, noção cunhada pela escola sociológica francesa, onde o tempo é uma categoria de pensamento $e_{3}$ como tal o re sultado de uma elaboração simbólica estabelecida dife. renciadamente pelas diversas culturas.

Sendo a ênfase dada ao carăter social, esse essudo procura acentuar a relatividade da noção ocidental do tempo em face não sơ das classificaçóes diversas das demais culturas, mas tambe̊m das diferentes modalida. des em que ela própria se expressa (historicidade, tradição, evoluçäo, revoluçäo, etc.). Por intermédio dessa concepção, introduziu-se nas análises sociais a noção de relatividade cultural do tempo e das suas múltiplas formas.

Hå uma diversidade de tempos sociais numa mes. ma sociedade, como tempo de trabalho, tempo obrigatório ligado ao trabalho, tempo de ocupação familiares, tempo livre, rempo biológico, tempo de ócio, etca, onde cada uma dessas categorias subdivide-se em outras. $O$ tempo de trabaiho pode ser aquele tempo profissional ou o da escola, por exemplo. O tempo obrigatório ligado ao trabalho, pode ser o tempo gasto em transporte, o tempo gasto com o serviço profissional. O tempo livre, também chamado de tempo liberado ao trabalho, pode ser aquele tempo de lazer, de práticas religiosas, polfticas e sociais. - tempo biológico \& aquele gasto para a alimentação, para sono. 0 tempo de bcio $b$ aquele que pertence ao

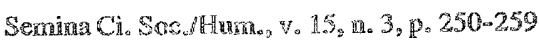

individuo como um direito único e do qual pode dispor como quiser, também chamado tempo discricional.

Há ainda a concepção de tempo incorporada pela economia, que teve sua origem extralda da noção do tempo social, onde se sobressai o controle de tempo. Esse, expressa um setor da área de organização empresarial responsável pela definição do tempo necessário para a realização de determinada função. Essa noção é hoje fundamental para determinar a produção de uma indústria, permitindo ainda, o cálculo de prêmios de incentivo, planejamento de trabalho e custos de produção.

Embora atualmente o processo esteja muito sofisticado, o procedimento para a determinação do controle de tempo partiu da observação do desempenho de funcionários experientes trabalhando normalmente, sendo suas atividades divididas em operações menores e, cada uma delas, cronometrada de forma precisa. São necessárias várias medições e os números são ainda corrigidos em função do esforço necessário para cada operação. O tempo total é dado pela soma dos tempos conseguidos, mais os perlodos de descanso, limpeza de equipamento, aquecimento da máquina, etc.

Dentro da concepção de tempo incorporada pela economia, poderlamos falar em tempo disciplinar, que é aquele vinculado aos condicionamentos individuais; em tempo de produção e circulação, que é aquele determinado pela tecnologia disponivel; em tempo do capital que é o da apropriação da natureza, da exploração do trabalho do homem, da extração do recurso natural, e que sobrepõe-se aos outros tempos.

As noções do tempo social e de tempo incorporado pela economia são hoje fundamentais para os trabalhos na ărea das ciências sociais, de uma maneira geral e, para os trabalhos geogråficos, de uma forma especifica.

A concepção do tempo histórico, o qual a Geografia herdou, caracteriza-se por dois tipos de sentidos históri. cos diferenciados. Um, refere-se a uma concepção clássica do tempo histórico e de seus estudos, que se dava de maneira erudita imparcial ${ }_{8}$ fechada sobre si mesma, separada do presente e baseada na visäo do fato e da cau. salidade histórica. Era a histórica que se fazia baseada na coleçäo dos "Grandes Estudos Históricos" (ARIES, 1989, p. 13). Seu instrumental de medida do tempo (sempre passado), eram os documentos e os mapas históricos encontrados nos arquivos, museus e bibliotecas nacionaise contados através da crônica, da história-narrativa, de maneira a mostrar a vida dos homens ${ }^{s}$ dominada por acidentes dramáticos; pelo jogo de seres excepcionais que al surgem, amiúde senhores de seu destino e mais ainda do nosso" (BRAUDEL, 1969, p. 24).

Essa concepção foi desacreditada ao considerar *se a história não unilateral pela disposição do tempo seccionado (dividido) por várias pequenas histơrias (as histơrias particulares' que dimensionam o real dos acontecimentos totais.

É necessário ainda considerar que os estudos do tempo para a filosofia estiveram sempre ligados à questão do ser, à ontologia, às procuras da existência humana. $O$ tempo, para a ontologia é de fundamental impor- 
tância porque o ser é compreendido como tempo.

Outra consideração importante é que muitas das teorias sobre o tempo foram formuladas com base no Princlpio de Causalidade que norteou o pensamento filosófico e cientffico moderno. Buscava-se a causa para tudo. Havia sempre um sujeito causador dos efeitos. Essa visão possibilitava que a realidade ficasse submetida a um tratamento técnico.

\section{3 - OS ESTUDOS SOBRE O TEMPO NA GEOGRAFIA BRASILEIRA}

\section{1 - OS ESTUDOS CLÁSSICOS}

Até 1940 os trabalhos no Brasil consideravam a pessoa do Geógrafo como um "viajante" no espaço e também no tempo. Esse tempo resumia-se na noção de passado, presente e futuro apreendidos na concepção histórica e na percepção das durações de momentos que se expressavam nas análises cartográficas e setoriais.

A obra de Paul Vidal de La Blache teve ampla djvulgação e, no Brasil, o próprio Delgado de Carvalho foi responsável pela difusão em larga escala da geografia regional vidalina, possibilitando nova dinamização aos estudos geográficos.

Sua maior contribuição foi no campo dos procedimentos metodológicos do ensino de Geografia onde atentou para a construção de um ensino não decorativo do nome de lugares e dos lugares, encontrando em La Blache a fundamentação necessária para refutar a idéia de ser a Geografia o estudo das localizações.

"Localizar os fenômenos e os fatos, foi o principal objetivo da geografia antiga, deixando o estudo dos fatos e fenómenos eles mesmos a outros ramos cientificos. Mais tarde foi feito um progresso: ao lado da localizaçäo toi foila a distit buição.. O terceiro estágio dos progressos geo. gráficos foi marcado pela impontancia sempre maior dada às correlaçôes existentes entre te. nómenos e fatos, as relações de causalidade $\theta$ de finalidade" (CARVALHO $1944, p_{0} 9 \%$

A partir de 1940, uma abordagem moderna do es. paço exprimia-se em unir teorias de "localizaçăo" e "distribuição" (que embasavam procedimentos analíticos an. tigos em Geografia) com a "correlação" dos fenômenos. Buscava-se, com o novo paradigma, relações de causalidades e finalidades e abria-se o caminho para o coroamento dos estudos regionais objetivando, assim, uma Geografia "descritiva", "explicativa" e "construtiva" \{O'REILLY, 1946\}.

A partir da obra de HARTSHORNE (1978) nos Estados Unidos, houve o desenvolvimento de estudos sistemáticos e uma crescente pluralidade de especializações tópicas que acabaram por originar - no Brasil no final dos anos 60 - reações ao paradigma regional que diziam respeito aos meios e métodos da Geografia. A crltica ao "excepcionalismo" da Geografia Regional, implícito nas proSemina Ci. Soc./Hum., v. 15, n. 3, p. 250-259 posições de Hartshorne, culminou na busca do desenvolvimento de leis geográficas para a distribuição espacial, a fim de que os geógrafos pudessem trabalhar dentro dos cânones do método científico geralmente aceito e libertar-se de seu isolamento acadêmico.

Nesse sentido, a busca de leis geográficas evidenciou um caráter de crítica ao enfoque histórico nas pesquisas geográficas, onde se afirmava que as fases sucessivas de um processo em desenvolvimento não eram efi-

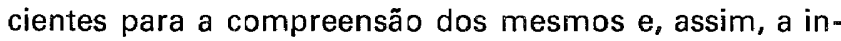
terpretação histórica do "método genético" (CAPEL, 1981; ESTÉBANEZ, 1983) efetivamente era improdutivo.

A partir dai, leis e teorias locacionais são largamente produzidas, originando inúmeros modelos explicativos que se estabeleceram como uma sistematização das teorias da difusão de inovações (corpo de doutrina que impõe uma ordem temporal rígida) tornado indispensável à interpretação dos fenômenos de localização, com base na New Geography.

Em 60 e 70, a qualidade aplicável dos estudos geográficos foi introduzida e divulgada amplamente. A Geografia descobria sua utilidade prática no planejamento, mas a análise temporal permanecia ainda nos moldes tradicionais.

Entre os anos de 60 e 80 duas séries de produções específicas desenvolveram-se, tanto na França, quanto nos EUA, com base no planejamento. Seus desmembramentos irão diferenciar a essência dos estudos derivados, pois uma originou trabalhos extremamente técnicos, pautados na quantificação e na tentativa de elaborar-se uma Geografia Aplicada e, outra, trabalhos extremamente críticos, embasados na denúncia de um mundo desigual e na possibilidade de se construir uma Geografia Ativa.

Duas vertentes foram-se gradativamente consoli. dando a partir dessa época a exemplo do que aconecie em outros paises: uma de cararter tenico o butra de ca. vâter crithice.

O salo que se verificou nos estudos geográticos atuais diz respeiro ao seu teor inerno. Jå näo impontava

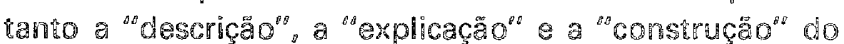
espaço. A possibilidade conquistada de correlaçăo de fe nômenos espaciais, levou-nos a buscar responder sobre as formas espaciais de organizações derivadas $e_{\theta}$ consequentemente, a tentar explicar essas organizações. Tal busca ocasionou o primeiro corte epistemológico que se assistiu na Geografia: um desvio do seu eixo central de preocupação. $O$ corte baseava-se na oposição dos pares aparência e essência a partir da aceitação comum da historicidade nos estudos geográficos.

\section{2 - A HISTORICIDADE NA GEOGRAFIA BRASILEIRA}

A discussão sobre o caráter do que é histórico, tendo como ponto de partida a atuação do homem e sua sociedade inventada como agentes do processo histórico, possibilitou o aparecimento de novas teorias e novo direcionamento aos estudos geográficos.

A partir da concepção de totalidade ${ }_{\diamond}$ tempo pas- 
sou a ser considerado como movimento total e particular e a consciência desse movimento, enquanto processo, estipulou a condição dinamizadora do movimento histórico universal. A reprodução da sociedade passou, assim, a ser um dado complexo, articulado globalmente. A totalidade subdividiu-se criando seus segmentos e a visão histórica permitiu a sua concreção. A preocupação com os seus processos foi relevante.

A análise da realidade deu-se por sua condição estrutural, e assim, novos agentes analíticos apareceram.

A subjetividade no processo da história, determinou os elementos componentes da realidade social: o espaço encontrou o seu sujeito histórico.

Os homens reais - agentes e sujeitos da história através da continuidade temporal pré-estabeleceram relações sociais que foram-se modificando. Mas existiram as determinações históricas que impuseram à sociedade e à história o seu próprio tempo, recriando-o no seu cotidiano.

A partir da aceitação do sujeito histórico, as ideologias passaram a ter importância significativa porque auxiliaram e possibilitaram o entendimento dos homens no processo produtivo, e assim, no movimento da sociedade. Elas estipularam-se, na Geografia, como uma critica.

A crítica ideológica partiu da consciência de que o saber não é neutro.

A questão social foi também colocada a partir da noção das sociedades históricas, onde a natureza passou a ser analisada do ponto de vista da sua socializaçäo.

Assim, o ser social foi concebido a partir do traba. Tho (divisão territorial do trabalho) que expressou as relações que se davam na produção de bens materiais e a natureza apresentou-se como um produto histórico.

Houve, portanto, toda uma reformulação das relações homem/natureza, onde se estabeleceu a relação su. jeito-objeto e consequentemente, a produção do espaço.

"... a historia é o homem-natureza se autotrans. formando pela via do trabalho em homem-sociedade, e o espaço, na verdade então espaçotemporalidade, é a forma geográfica de realização desse movimento organizado da história" (MOREIRA... [19..]).

A partir dessa mudança estrutural, o próprio espaço foi rediscutido, pois sendo considerado produto da história, que tem suas determinações históricas, deslocou o sujeito do âmbito da relação história-natureza.

Passaram a ser categorias elementares da análise espacial os modos de produção e a formaçäo econômica e social, onde o modo de produção deu-se como um processo que se desenvolveu na continuidade histórica "de forma contraditória e múltipla, temporal e espacialmente descontinuo, num movimento desigual e combinado" (MORAES, 1986, p. 48) e a formação econômica e social tratou da "evolução diferencial das sociedades, no seu quadro próprio e em relação com as forças externas..." (SANTOS, 1977, p. 82).

Os modos de produção concretizaram-se sobre Semina Ci. Soc./Hum., v. 15, n. 3, p. 250-259 uma base territorial historicamente determinada que expressou sempre a sequência impositiva do novo sobre o velho, embora isso não ocorresse plenamente. Já, a formação econômica e social compreendeu uma estrutura produtiva e técnica dada pela distribuição da atividade de produção.

\section{3 - O ESTUDO DO TEMPO DO PONTO DE VISTA DA HISTORICIDADE}

Alguns geógrafos preocuparam-se especialmente com a concepção temporal nos estudos geográficos. Destacaremos as suas proposições teóricas averiguando a ordem de prioridade em que tais preocupações se pautam e suas respectivas diferenças.

\subsection{1 - O tempo nos estudos de Milton Santos}

Milton Santos é um teórico de grande influência na Geografia brasileira. Sua obra nos interessa devido a longa preocupaçăo que traz com o conteưdo temporal.

Das contribuições que ele elaborou até agora, merecem destaque a que trata do tempo espacial e a proposta de congruência entre sistemas temporais e sistemas espaciais.

Milton Santos propõe o espaço como um conjunto de formas que estabelecem as relações sociais através do tempo, contendo uma estrutura social de relações presentes manifestas por processos e funções.

"O espaço é, então, um verdadeiro campo de forças cuja aceleração é desigual. Dal porque a evolução espacial não se faz de forma idêntica em todos os lugares." (SANTOS, 1977, p. 122)

A concepção aí embutida é a de ser o espaço concebido como uma instância social, ou seja, essa estrutura da sociedade apresenta como fato especifico a existência das coisas produzidas e as suas relações de coexistência a simultaneidade, ordem ou desordem. Apresenta também o estabelecimento de formas geográficas fixas ligadas ao modo de produçäo precedente ou ligadas a um de seus momentos.

Entende-se por essa via, o espaço organizado como um resultado concreto de múltiplas variáveis que se integram historicamente, sendo uma estrutura dinâmica que se manifesta pelo fator atrativo do trabalho, do capital, das infra-estruturas, etc. É também reconhecido como resultado da produção, tendo cada atividade uma ordem espaço-temporal.

O espaço é portanto uma realidade objetiva e histórica que se impôe aos individuos, um colaborador da reproduçăo das relações sociais, aparecendo também como mercadoria.

Ao serem mudados os objetos e as formas de produção, a relação do homem com a natureza também já não \& mais a mesma, assim como as relações sociais também não o são. Significa dizer que há um novo comando temporal, uma nova organização espacial. 
"Ora, cada vez que o uso social do tempo muda, a organização do espaço muda igualmente." (SANTOS, 1977, p. 163)

Para Milton Santos, a compreensão dos fenômenos só é possivel a partir de um enfoque espaço-temporal, onde o tempo se estabelece a partir da noção de espaço relativo ("um sistema de relações, um campo de forças"). Assim, o tempo é tido como uma variável geográfica, não sendo um conceito absoluto, mas relativo; não sendo uma forma perceptiva e, sim, concreta; não sendo seccionado e, ainda, dotado de características particulares.

"O Ser é a sociedade total; o tempo são os processos, e as funções, assim como as formas são a existência. As categorias fundamentais do estudo do espaço são, pois, a totalidade e o tempo; mas o acontecer sobre o espaço não é homogêneo, a noção de lugar e de área se impõem, impondo ao mesmo tempo a categoria da escala, isto é, a noção de fração de espaço dentro do espaço total." (SANTOS, 1977, p. 176)

A sucessão de sistemas espaciais demonstra o valor relativo de cada lugar através da história. Milton Santos identifica, com essa consideração, os sistemas temporais.

Para ele, a idéia de tempo é aliada a uma idéia de sistema, o que significa dizer que nem sempre o passado explica o presente, se a busca da explicaçăo for interessada apenas num elemento do conjunto.

"Como um elemento não pode evoluir isolada" mente, nem é capaz de se transformar sem ar" rastar os demais no movimento, o nosso proble. ma não e o da evolução panticular de um el⿳

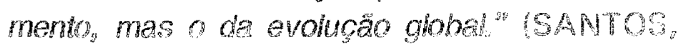
197,902083

Exhtem as variaveis que introdudem as nudanges?

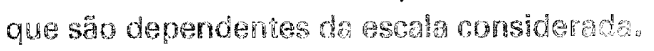

o espaç \& quathicato diferentemente cuando no. vas variaveis se inctam porone elas astabeleren nover

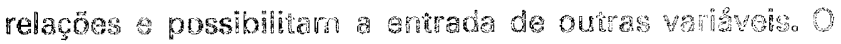
espaç combine, entâ, o veho com novo, estabete. cendo superposicóes entre os sistemaso

Para Miton Santos, no estudo do presente neces. sário, portanto, considerat os sucessivos sistemas âemporais e espaciais, o que significa identificar periodos isolar fatores dinâmicos próprios, estabelecendo a dị̂. rença de idade entre os elementos.

Devido à hierarquia das inovações, as moderniza ções geram superposiçăo entre vărios espaços onde, em cada lugar, as combinaçóes se däo especificamente sendo, essa particularidade, temporal e espacial. Assim. Milton Santos fala de um tempo espacial próprio de cada lugar que identifica uma combinação única e asse gura a unidade do contínuo e do descontínuo lassincro. nia dos lugares e sincronia do todo).

Semina Ci. Soc./Hum., v. 15 , n. 3, p. 250-259
"Dentro de cada sistema historico as variáveis evoluem assincronicamente; mas o sistema geográfico muda sincronicamente." (SANTOS, 1977, p. 211)

A velocidade de mudança de uma variável não im pede a coerência interna de um sistema espacial quando ele é substituldo por outro, pois essa variável se recria $a_{\text {já }}$ que as variáveis são as mesmas.

Seu estudo avança na medida em que identifica os sistemas temporais apresentados na escala mundial. Cinco períodos de sucessões coincidentes com as modernizações são apresentados por ele:

O primeiro (fins do século XV até 1620) seria refe. rente ao comércio em grande escala, o segundo seria equivalente ao perlodo manufatureiro $(1620-1750)$ o o rer ceiro, permearia a Revoluçäo Industrial (1750-1870), o quarto, o periodo industrial (1870-1945) e o quinto e pre. sente momento, equivalente ao periodo tecnológico, que se iniciou no fim da Segunda Grande Guerra, quando a tecnologia (enquanto pesquisa concretizada) subordina as outras variazveis espaciais. O primeiro, quarto e quinto periodos seriam fundamentais para entendermos as mo. dificações ocorridas nos paises subdesenvolvidos.

SANTOS (1988c $c_{e}$ p. 29) estabelece uma diferença fundamental entre os quatro primeiros sistemas tempo. rais e o quinto, já que no último, "todos os espaços são aicançados imediatamente por um certo número de mo. dernizações".

A organização do espaço acontece em sintonia com os fatores de dispersão e concentração através da hisṫ. ria. No presente, esses fatores contribuem para a con centraçäo espacial e "säos essencialmente, o tamanho das empresas $_{s}$ a indivisibilidade das inversôes e as "econo. mias" e externalidades urbanas a de aglomeração neces.

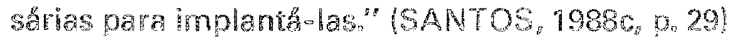

Os tarores de dispersäo representam sh pelas uru

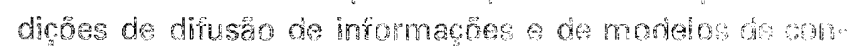

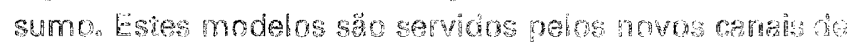

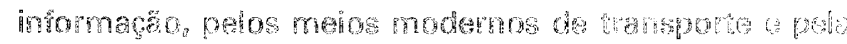

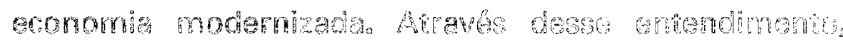

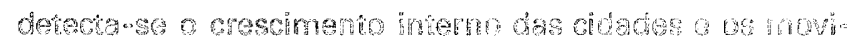
mantos migratrios.

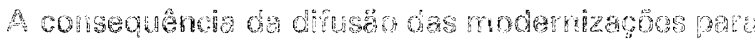

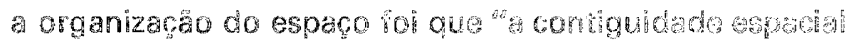
deixou de ser uma condiça imoerative ISANTOS. 1988c, p. 30). A possibilidade de imporar inovacoes in. corporadas advindas das inovacoues induzidas dos paises industrializados para os subdesenvolvidos, jä năo depen. de dos centros existentes no prốprio pais, que podem rem ceber inovaçōes incorporadas independente da criação ou da expansão da área de inovações induzidas, devido ao progresso dos transportes e meios de comunicação.

A consequência de uma modernização e̊ gerar um efeito de especialização, passando a existir uma hierar. quia espacial.

Milton Santos estipula novo avanço à sua proposta ao sugerir novos conceitos na análise categorial de uma geografia global, quando discute mais detalhadamente a 
paisagem do ponto de vista da heterogeneidade do espaço habitado e quando detal ha as noções de fixo e fluxo para a análise da configuração territorial. Na questão temática do tempo, mais recentemente introduz a idéia de regime e de rutura. $O$ regime estipula-se pelo conjunto de variáveis que não evoluem homogeneamente mas relacionam-se equilibradamente durante um tempo, devido à existência de uma organizaçäo eficaz que impõe regras de ação. Quando a eficácia da organização se perde, a rutura acontece preconizando um "sinal de crise e de passagem a um outro periodo" (SANTOS, 1988a, p. 83).

Milton Santos vem continuamente reformulando e acrescentando novos detalhes às suas proposições. São inúmeros os textos que poderiam ser mencionados, no entanto, optamos por nos prender aos trabalhos que consideramos ser os de mais longo alcance, expressando significativamente sua contribuição. Essa foi uma sintese das idéias básicas do autor, sendo sua obra, atualmente, bem mais ampla e seu pensamento está além do que aqui expusemos.

\subsection{2 - Diferentes visões do tempo na Geografia Humana Brasileira}

Vários sãos os geógrafos que, apesar de não trabalharem especificamente com o tempo, como é o caso de Milton Santos, contribuiram para o avanço desse estudo na Geografia. Seus trabalhos foram averiguados e são aqui apresentados com a preocupação de diferenciarmos pontos de vista, tanto em termos de noção como em termos de desenvolvimento dos conceitos. Assim, dada às inúmeras considerações sobre o tempo que se encontram aqui e ali nas publicações geográficas, aquelas que nos pareceram mais especificas dentro da temática aqui tratada, serão abordadas.

OLIVEIRA (1981) em um artigo publicado em Novos Rumos de Geografia Brasileira, defende o avanço dos estudos geográficos a partir da compreensão materialista dialética do espaço e do tempo. Discute inicial. mente a luta tebrica entre o idealismo e o materialismo dialético ${ }_{\nu}$ e segue desenvolvendo as concepções de espa. ço e tempo sob o modo capitalista de pensar.

São verificadas as questões da objetividade do espaço e do tempo; do espaço como extensăo, como ordem, princípio e lei de coexistência dos fenômenos; o tempo como duração, como lei de mutação dos fenômenos; a infinitude do espaço e do tempo, sua continuidade e descontinuidade; todas essas questões vistas a partir de vários filósofos e cientistas como Aristóteles, Copérnico, Galileu, Newton, Leibniz, Kant, etc.

Por fim o autor apresenta a concepção materialista dialética do espaço e do tempo, discorrendo sobre a sua essência contraditória, as suas particularidades, a sua natureza infinita, a sua continuidade e descontinuidade, a sua unidade, diversidade e interdependência, defendendo - avanço que tal concepção estabelece para a análise geográfica.

MOREIRA, no artigo A Geografia serve para desvendar máscaras sociais (MOREIRA, 1982), proSemina Ci. Soc./Hum., v. 15, n. 3, p. 250-259 põe uma discussão sobre o espaço social e o espaço tempo.

Afirma o autor que todo objeto tem uma dimensão temporal e espacial e que os geógrafos abstraíram-se da dimensão temporal em seus estudos ao separarem o espaço do tempo.

Assim, o tempo para Ruy Moreira é espaço-tempo, num movimento dialético, cheio de continuidade e também de descontinuidade. Cada perfodo da história compreende formas especificas de relações de produção.

“A introdução da dialética espaço-tempo nos estudos de geografia é fundamental para compreender-se as leis de movimentos das formações espaciais e seu conteúdo histórico." (MOREIRA, 1982, p. 45)

Os textos de A.U. de Oliveira e de R. Moreira são fundamentais para a compreensão do corte epistemológico ocorrido na Geografia a partir das duas últimas décadas. Oliveira produziu um trabalho crítico onde coloca toda a evolução dos estudos do tempo e, especifica como deve ser considerada a dimensão temporal a partir do materialismo histórico dialético em sua conceituação básica. Moreira discute a descoberta da historicidade nos estudos geográficos, a partir dos pensadores filósofos e geógrafos que a propuseram, estipulando uma nova interpretação histórica. Assim, nenhum trabalho que se pretenda também temporal deve ser concebido sem tais leituras.

Armando Corrêa da Silva, geógrafo preocupado com a questão da liberdade e do lugar, faz considerações importantes a respeito do tempo nos estudos geográficos. Afirma que é preciso tomar o espaço em si como ocorrência material, como espaço absoluto, relativo e relacional, situando a questão do tempo quando especifica o movimento.

O seu ponto de partida é o espaço ontológico , o Ser como espaço e o espaço do Ser relacional. Assim ${ }_{t}$ o movimento das coisas terão significação especial para esse geógrafo, cujo método nos leva ao centro de suas ques. töes onde radica a problemática da existência humana.

Sua proposição volta-se para os homens que däo vida e sentido ao espaço. Mas esse homem é uma entidade individual, social, falivel, angustiante, solitária, alegre, quer dizer, cheia de atributos humanos, emocionais e racionais. Assim, o espaço adquire também essa dimensão humana.

A sua teoria visa uma maneira de considerarmos tal enfoque nas análises geográficas: a "Ontologia Analítica". 
Surge a possibilidade da teoria, na ontologia do espaço." (SILVA, 1986, p. 54)

Espaços e tempos são diferentes, anormais e desiguais, sendo atributos da sociedade, que continuamente se transforma. Assim, toda a mudança externa experimenta uma mudança interna.

"Mudar o lugar é mudar a consciência; mudar de lugar é mudar a consciência." SILVA, 1986, p. 54)

A dialética existente entre a produção do lugar e do ser, estabelece um conceito e uma comunicação particularizada e universal, dado à equivalência dos lugares. Assim, o movimento é espaço-temporal e ultrapassa, a cada mudança, a sua determinação.

A Geografia estuda os corpos a partir da dimensão do tempo presente e por causa disso, estabelece seu elo com o passado e o futuro, pois o espaço em movimento é mudança.

"O movimento do espaço e do tempo presente no espaço move-se, em Geografia, da unicidade para a dependência, para a equivalência. Por isso, expressar o espaço e o tempo em Geografia é realizar a análise dos lugares e das relações." SILVA, 1986, p. 99)

Acredita 0 autor, que não existem relações espaciais, mas relações entre corpos em continua movimentação no espaço. Essa é a dinâmica que possibilita a transformação das coisas nos lugares onde se dão.

"Por isso, ainda, o lugar e a relação são, como dados, uma totalidade complexa de contradições, que se resolvem como sociedade em movimento, no lugar e, por isso, do lugar." SILVA, 1986, p. 100)

Estabelecida essa determinação do movimento do ser, o conceito e o discurso aparecem ("linguagem-conceito") expressando-se na História e na Historiografia. Se aparecem, expõem-se ficando sujeitos - o conceito e o discurso - à consciência, às determinações do movimento e da transformação, sujeitos à uma nova conceituação, portanto.

Notamos a preocupação do autor, no que diz respeito a uma determinação consciente das dimensões espaço-temporais, o que significa dizer que ele inclui a dimensão subjetiva do espaço e do tempo em seus estudos, embora essa não seja determinante. Sua preocupação está no valor referencial e diferencial que os lugares adquirem, em função dos elementos internos e externos que the caracterizam a existência em diferentes épocas.

"É que, por isso, o movimento da estrutura se póe, ao mesmo tempo, como estrutura em movimento. Isso quer dizer que o espaço é tempo

Semina Ci. Soc./Hum., v. 15, n. 3, p. 250-259 do espaço e o tempo é o espaço do tempo. Mas esse espaço-tempo é um espaço-tempo alheio para si - ou um espaço-tempo exterior - para outro. $A$ ação consciente torna-se sobreconsciente e se põe como referência." SILVA, 1986, p. 54)

Devemos observar que mencionamos aqui, as idéias básicas do autor, cujas proposições em muito já avançaram.

Em artigo publicado na revista Terra Livre, RIBEIRO (1988) considera, a partir das transformações que o modo de produção capitalista trouxe às relações entre as pessoas e, especialmente, a partir da venda da força de trabalho da classe trabalhadora, a perda da livre escolha do que fazer com o seu tempo, ritmo e produção. Sua preocupação é com o controle estabelecido pelos poderes que se aproveitam das tecnologias para imprimir na realidade materializada um ritmo próprio ao capital e às re lações que se estabelecem.

Constituinse também um trabalho diferenciado, na medida em que parte "do pressuposto que o espaço produzido é a materialização do tempo, através do trabalho dos homens. E que o tempo tem na gênese do espaço, um aspecto objetivo, que é o contato com o espaço, e outro subjetivo, que se passa na produção do tempo. atravês do pensamento." (RIBEIRO, 1988, po 46)

O autor considera o tempo do trabalho, sua apropriação e o tempo livre como embasadores do tempo social.

Mais recentemente, em artigo publicado no Boletim Paulista de Geografia, RODRIGUES (1989) parece esta. belecer uma outra vertente na produção de estudos que consideram o tempo.

Esse trabalho, fundamenta-se na investigação do tempo livre do trabalhador que foi apropriado como parte de um projeto de controle social pelas ideologias políticas dominantes, desde a Segunda Guerra Mundial. Estabelecido como férias e redução da jornada de traba. Iho, o tempo livre é analisado através das conquistas por parte dos trabalhadores e também pela necessidade dos empresários de controlar a produçăo e o desemprego. Hoje, esse tipo de controle do tempo livre é principal. mente projetado pelas empresas de turismo, enquanto apropriação e dominação. O tempo livre aqui, \& tratado como tempo social.

\section{4 - O TEMPO NA ANÅLISE GEOGRÅFICA ATUAL: CONSIDERAÇÕES}

As transformações espaciais assistidas na atualidade chegam a ser desconcertantes e um esforço maior por compreendê-las tem sido feito via a análise do trabaho, da apropriação e do poder.

A Geografia parece ter-se disposto a reformular também as questões temporais no presente perlodo. Isso vem sendo assistido desde a década de 80 , mas sua expressão maior enseja tomar vulto agora.

É evidente a pluralidade de pontos de vista que vão 
desde a preocupação com superposições temporais, aqueles atentos para a velocidade dos acontecimentos, até os que se estabelecem via o cotidiano do trabalho e das relações sociais.

Vimos que a dimensão temporal nos estudos geogrăficos evolui a partir da concepção da historicidade dos processos espaciais. Isso porque a historicidade estipulou a totalidade desses processos, passando a consideră-los como movimentos totais e particulares, complexos e articulados. A visão histórica foi quem permitiu agregá-los。

A proposta de Milton Santos volta-se para a preocupação de periodizar essa totalidade, colocando os movimentos particulares em consonância com os movimentos do todo. Acredita que esse esforço nos leva a mais exata compreensão das estruturas e processos espaciais.

Assim, as variáveis modernizadoras, que são temporais e espaciais, têm importância fundamental pois elas indicam e causam as mudanças. Portanto, devem ser identificadas e isoladas a fim de podermos apreender o tempo espacial próprio de cada lugar.

Mas este não é um trabalho fácil porque as variắveis são e têm temporalidade, o que significa dizer que quando lidamos com processos dinâmicos as variáveis se fundem, confundem e transformam-se. Então, elas estão camufladas temporal e espacialmente. SANTOS $(1988 \mathrm{c}$ p. 23) soluciona o problema:

"Em meu caso, o objetivo é o de encontrar, através da História, secçöes de tempo em que, comandado por uma variável significativa, um conjunto de variáveis mantém um certo equillorio, uma centa forma de relaçóes. Cada um desses periodos representa, no centro do sistema, um conjunto coerente de tormas de ação sobre os paises da periferia. A evolução dos espaços pe. riféricos toma, então, em cada perodo, caminhos similares."

Como podemos perceber, o comportamento dos movimentos particulares possibilitará a identificação das variåveis modernizadoras significativas, embora o ponto de partida seja sempre o movimento total.

Para SILVA (1986), a questão central estå na apreensão dos processos espaciais. Significa dizer que seus estudos preocupam-se com o funcionamento da operação mental quando nos propomos a uma análise espacial e quando temos algo a dizer sobre ela. Nesse sentido, o tempo em seus estudos apresenta-se como urna deierminaçăo do movimento e do momento dos corpos no lugar, tendo importância na medida em que apreende as transformações espaciais em sua temporalidade também. O tempo e o espaço são, portanto, relacionais.

O tempo sobrecarrega-se de atributos subjetivos, assim como o espaço, pois sua relação estả cheia de elementos perceptivos, psicológicos a cotidianos. É por isso que o lugar e as suas relaçöes têm privilégio nos estudos desse geógrafo. Cada lugar, é para ele, uma totalidade complexa, atual e em constante movimento.

Semina Ci. Soc./Hum., v. 15, n. 3, p. 250-259
Com relação ao trabalho de RIBEIRO (1988) e RODRIGUES (1989), poderíamos falar no estabelecimento de estudos microtemporais na Geografia, ou seja, análises que consideram uma pequena faceta das séries temporais existentes ou de sua apreensão. Não significa dizermos que tais trabalhos são inexpressiveis, pelo contrário, evidenciam uma tendência promissora nos estudos geográficos que podem contribuir significativamente para o avanço das análises geográficas.

\section{4 - CONCLUSĀO}

Vimos os problemas referentes a uma determina ção dos estudos temporais, como esses estudos se deram na Geografia até os dias atuais e quais as estruturas sociais do presente onde a análise temporal deve evoluir.

Duas séries de observações fazem-se necessárias, portanto.

Uma, diz respeito aos estudos que investigam a sociedade enquanto uma estrutura particular. Fazem parte desses estudos, aqueles que consideram o cotidiano das cidades, do campo, das fábricas, dos micropoderes, etc., considerando, inclusive, o seu imaginário coletivo. Os fenômenos espaço-temporais quando al considerados, adquirem dimensões muito próprias.

Outra, diz respeito aos estudos que delimitam uma estrutura de acontecimentos globais e sua configuração social, que finalizarm a detecção de eventos espaço-tem-. porais de mais larga abrangência, que darão suporte ao entendimento de variåveis menores.

o certo é que o incessante e acelerado avanço das descobertas cientificas e técnicas e a inter-relaçäo cada vez mais forte entre elas, dificulta a análise dos efeitos que produzem. As consequências positivas e negativas deste complexo processo não resulta em algo simples.

As pesquisas se fazem avançadas na Geografia, porêm, devemos esperar que as contribuições sejam enriquecidas, dado aos ágeis e complexos atributos cada vez introduzidos mais intensamente no espaço.

Em Geografia, todos admitem, o tempo presente seu entendimento e disposição - é uma das categorias analiticas de primeira ordem. Trabalha-se com os acontecimentos na dimensão do presente.

Em que medida o passado interessa? Essa questäo, embora muito discutida pela Geografia Clåssica, não foi suficientemente detalhada, e por isso entendemos que os abusos ocorridos no tratamento histórico dos fenômenos espaciais, deram-se devido a essa falta de esclarecimento.

A Geografia atual parece resolver esse problema quando estabelece o passado que interessa, aquele que se apresenta como indício para o entendimento do presente: 0 passado do modo de produção capitalista. Le vantando sua evolução, seus dados e subperiodos, fundamenta-se para a compreensão mais aprofundada do presente.

Mas o tempo passado acompanhou a peculiaridade da fragmentação dos espaços, resultando, da mesma maneira, fragmentado. Essa consideração tem se coloca. 
do mais enfaticamente, esiando os geógrafos preocupados em subdividir o tempo de acordo com os acontecimentos espaciais. Demonstramos, por exemplo, a periodização de SANTOS (1988) e a análise fragmentar de RODRIGUES (1989).

Quando trabalhamos com a fragmentação do espaço, a problemática adquire uma maior dimensão. A consideração sobre os lugares (para Armando C. da Silva) ou subespaços (para Milton Santos), remete, pois, a um entendimento que se coloca como muito próprio, já que estipula a constituição de um universo de elementos únicos e agregadores.

A dúvida a que chegamos é sobre a existência de uma teoria que consiga dar conta, ao mesmo tempo, das realidades maiores e menores da totalidade-mundo.

Ainda, vimos que o problema do tempo levanta questões de ordem cognitiva e que se referem, em primeiro lugar, à sua região de existência. Se o admitimos como um fenômeno objetivo, o resultado da análise apresenta-se diferenciado daquele em que o tempo se estabelece a partir de regiões subjetivas. destacar

Há uma outra questão que nos parece importante

Alguns geógrafos, como por exemplo Milton Santos, trabalham com o tempo histórico na medida em que se preocupam com uma periodização. Esse é um dos critérios de suas análises.

Outro critério que se faz necessário distinguir, é que eles trabalham, tambe̊m, mas com caracteristicas diferenciadas, com as variáveis que têm qualidades espaço-temporais. Significa que essas variáveis, no tempo, transformam (no espaço) o velho em novo (misturam-se, além disso), mas são também, elas próprias, velhas e novas em sua temporalidade.

Essa consideração, nos levou à compreensầo de que uma coisa é situarmos a pesquisa no tempo $e_{8}$ outra bem diferente, ê considerarmos, na anålise, a temporalidade dos elementos com os quais trabalhamos.
Cremos que os problemas aparecem mais fortemente nessa última situação porque os elementos, além de serem e estarem camuflados em sua ordenação e estabelecimento, são substituldos e novamente introduzidos no espaço com agilidade e rapidez, impondo dificuldades para serem trabalhados.

Nesse âmbito, as questões temporais mais se complicam, pois a vida moderna é vasta de elementos temporais. Estamos ainda por fazer tal distinção.

As variáveis espaço-temporais são múltiplas e devem ser melhor detectadas, mas os elementos temporais estão por se construir. Sabemos que existem, admitimos sua existência e, no entanto, perguntamos quais são. Não sabemos como enumerá-los, como ordená-los e sistematizá-los.

Obtivemos indicios:

1) no tempo das trajetórias e nas suas consequências;

2) nas técnicas de controle do tempo e nas suas consequências;

3) na simultaneidade característica do nosso tempo: simultaneidade das informações, da imagem, dos acontecimentos, das relações e suas consequências;

4) na idéia de "encurtamento" do tempo referida à própria temporalidade de nossa época;

5) na questão dos referenciais ou como preferem alguns autores desreferenciais, que nos leva a identificar uma temporalidade diferenciada;

6) na questão dos ritmos impostos à vida moderna, que estabelece um andamento próprio do cotidiano e apresenta-se repleto de simbolos e alegorias tecnológicas.

Uma vez que esse trabalho tenta se estabelecer como uma sintese, esforçamo-nos para que ofecesse uma visão generalizada dos problemas que envolvem a análise temporal, visando a Geografia Humana e suas perspectivas. Esperamos que algumas dessas sugestőes possam vir a contribuir na formulação propostas de trabalho em ramos mais amplos da pesquisa. Esta 8 a ex. pectativa que formulamos aqui.

SALVI, $R_{0}$ The Studies of the Time in the Brazilian Human Geography。 Semina: $\mathrm{Ci}_{0}$ Soc./Hum $\mathrm{H}_{0}$ Londrina, $\mathrm{V}_{0} 15_{y}$ n. 3, p. 250-259, Sept. 1994 .

ABSTRACT: This work aims to understand the conceptions of Time in Brazilian Human Geography, since classical school to the present day, with special emphasis on the propositions of Milton Santos among other contemporary geographers.

KEY-WORDS: Geography, Time, Temporality, Space, History, Historicity, Evolution of geograpical knowledge, Geography epistemology.

\section{REFERÊNCIAS BIBLIOGRÁFICAS}

ANDRADE, A. As Duas Faces do Tempo. Rio de Janeiro: José Olímpio, 1971.

ANDRADE, M.C. Caminhos e Descaminhos da Geografia. Campinas: Papirus, 1989.

Semina Ci. Soc./Hum., v. 15, n. 3, p. 250-259
ARIES, P. O Tempo da História. Rio de Janeiro: Francisco Alves, 1989.

BALASTRERI, A.A. Tempo livre como objeto de consumo e lazer dirigido como oportunidade de manipulação. Boletim Paulista de Geografia, São Paulo, n. 67, 1989. Semestral. 
BRAUDEL, F. Écrits sur l'Histoire. Paris: Flammarion, 1969.

CAPEL, H. Filosofia y Ciencia en la Geografia Contemporánea. Barcelona: Barcanova, 1981.

CARV ALHO, D. de A. Orientação Moderna. Boletim Geografico, Rio de Janeiro, v. 12, n. 1, mar. 1944.

-D. de A. O Sentido Geográfico. Boletim

Geografico, Rio de Janeiro, v. 40, n. 1, jul. 1944.

CENTRO CULTURAL DE CHÂTEAUVALLON. Une Leçon d'Histoire de Fernand Braudel. Paris: Les Editions Arthaud-Flammario, 1986

CostA, R.H. Filosofia, Geografia e Crise da Modernidade. Terra Livre, São Paulo, n. 7, 1990.

CHRISTOFOLETTI, A. Perspectivas da Geografia. São Paulo: DIFEL, 1982.

ESTÉBANEZ, J. Tendencias y Problematica Actual de la Geografia. Madrid: Editorial Cincel, 1983.

FOCK, V. The Theory of Space, Time and Gravitation. Oxford: Pergamon Press, 1966.

FRIEDMANN, G. Le Travail en Miettes, Spécialisation el Loisirs。 Paris: Gallimard, 1964.

GEORGE,P.; GUGLIEMO, R.; KAYSER, B.; LACOSTE, Y. A Geografia Ativa. Difusão Européia do Livro, 1968.

GRÜNBAUM, A. Espaço e Tempo. Filosofia da Ciência São Paulo: Cultrix, 1979.

HARTSHORNE, R. Propósitos e Natureza da Geografia. São Paulo: HUCITEC/EDUSP, 1978.

HAR VEY, D. Explanation in Geography. London: Edward Amoid, 1973.

KUHN, T.S A Estrutura das Revoluçōes Cientficas são Paulo: Perspertiva, 1982.

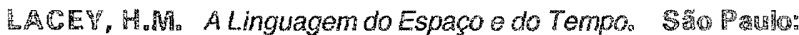
Perspectiva, 1972

LACOSTRE, Y. La Géographie, ça sert, daabord, à faire la Guerre. Paris: Ediltions La Descouverte 1985.

MORAES, A.C.R.; GOSTA, W.M. Geografia Crfica: A Valorizaçăo do Espaço. São Paulo: HUCITE[ 1984.

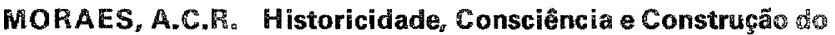
Espaço: notas para um debate. IN: SOUZA, M.A. de: SANTOS, M. A Construção do Espaço. São Paulo: Nobeli 1986.

MOREIRA, R. (Org.). Geografia: Teoria e Critica. Petrópolis: Vozes, 1982.

MOREIRA, R. Assim se passaram dez anos (A Renovaçăo da Geografia no Brasil: 1978-1988). [s.l.]: [19..]. Xerox.

MUMFORD, L. The myth of machine. Nova York: Brace and World, 1966.
OLIVEIRA, A.U. de. Espaço e Tempo: compreensão materialista dialética. IN: SANTOS (Org.). Novos rumos da Geografia Brasileira. São Paulo: HUCITEC, 1988.

O'REILLY, H. A Geografia e o Homem. Boletim Geografico, Rio de Janeiro, v. 40, n. 4, jul. 1946.

QUAINI, M. A Construçáo da Geografia Humana. Rio de Janeiro: Paz e Terra, 1983.

RIBEIRO, W.C. Relação Espaço/Tempo: considerações sobre a Materialidade e Dinâmica da História Humana. Terra Livre, São Paulo, n. 4, 1988.

SANTOS, M.; SOUZA, M.A. de (Orgs.). OEspaço Interdisciplinar. São Paulo: Nobel, 1986.

SANTOS, M. Sociedade e Espaço: a formação social como teoria e como método. Boletim Paulista de Geografia, São Paulo, n. 54, 1977.

Janeiro, 1979

- Espaço e Sociedade. Petrópolis: Vozes. Rio de Economia Espacial: Crficas e Alternativas. São Paulo: HUCITEC, 1979.

\section{6.}

Por uma Geografia Nova. São Paulo: HUCITEC.

- Metamorfoses do Espaço Habitado. São Paulo:

HUCITEC, 1988a.

O Espaço Geográfico como Categoria Filosofica.

Terra Livre. São Paulo, n. 5, 1988b.

Espaço e Método. São Paulo: Nobel, 1988c

A Revoluçáo Tecnologica e o Território:

Realidades e Perspectivas. Terra Livre. São Paulo, n. 9, 199 .

SILVA, A.C. da. A Geografia e a Questão da Forma. Seleçáo. de Textos, São Paulo, 1929

Fenomenologia e Geografia.

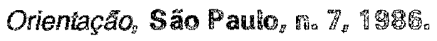

Cullura. São Paulo: HUCITEC, 1986

HUCHTEC, 1988.

OEspaço fora do Lugar. São Paulo:

Ponto de Vista - O Pós-Marxismo e o Espaçe

Cotidiano. Terra Livre. São Paulo, n. 7, 1990.

Ontologia Analltica: teoria e método. Terra

Livre. São Pauło, n. 9, 1991

SOUZA, M.A. de; SANTOS, M. (Orgs.). A Construçắo do Espaço. São Paulo: Nobel, 1986.

SZAMOSI, G. Espaço e Tempo: as dimensões gêmeas. Rio de Janeiro: Jorge Zahar, 1988.

Recebido para publicação em 4/4/1994.

Semina Ci. Soc. $/$ Hum., v. 15 , n. 3, p. 250-259 